\title{
DETERMINATION OF SOME PHYSICAL AND MECHANICAL PROPERTIES OF POTATO TUBERS RELATED TO DESIGN OF SORTING, CLEANING AND GRADING MACHINE
}

\author{
Yossry B. Abd Elhay*
}

\section{ABSTRACT}

Due to the lack of information about the physical and mechanical properties of potato in Egypt which are very important to understand the behavior of the product during the post harvesting operations such as harvesting, transporting, sorting, grading, packaging and storage processes and also, it is necessary in processing operations such as cooling, drying and all heat and mass transfer processes . The main objective of this work to study the physical and mechanical properties of potato to form an important database for three of the most popular cultivars (Astrix, Diamont and Santana) in Egypt. These properties include: dimensions, mass, volume, , true density, sphericity, geometric diameter, arithmetic diameter, friction angle and rolling angles with different surfaces such as rubber, galvanized steel sheet, Iron sheet and aluminum in order to determine the best post-harvest options. Mean values of length, width, thickness, mass, volume, true density, sphericity, geometric diameter, and arithmetic diameter were $74.99 \mathrm{~mm}, 47.79 \mathrm{~mm}$, $38.65 \mathrm{~mm}, 96.35 \mathrm{~g}, 72525.128 \mathrm{~mm}^{3}, 1.176 \mathrm{~g} / \mathrm{cm}^{3}, 69 \%, 51.74 \mathrm{~mm}$ and $53.81 \mathrm{~mm}$, respectively for potato tubers "variety of Astrix". Meanwhile were $64.79 \mathrm{~mm}, 45.12 \mathrm{~mm}, 39.81 \mathrm{~mm}, 78.41 \mathrm{~g}, 60935.148 \mathrm{~mm}^{3}, 1.149$ $\mathrm{g} / \mathrm{cm}^{3}, 75.35 \%, 48.22 \mathrm{~mm}$ and $49.91 \mathrm{~mm}$, respectively for potato tubers "variety of Diamont". And for variety of Santana were $98.78 \mathrm{~mm}, 58.19$ $\mathrm{mm}, 44.14 \mathrm{~mm}, 167.21 \mathrm{~g}, 132845.954 \mathrm{~mm}^{3}, 1.193 \mathrm{~g} / \mathrm{cm}^{3}, 64.10 \%, 63.31$ $\mathrm{mm}$ and $67.04 \mathrm{~mm}$, respectively. The maximum friction angle of 28.6, 22.2 and 30.4 degree and rolling angle of 24.8, 20.2 and 27.4 degrees were obtained with rubber surface. While, the minimum friction angle of 16.3, 14.0 and 18.7 degree and rolling angle of 14.0, 13.3 and 15.5 degree were obtained with aluminum surface for Astrix, Diamont and Santana potato varieties, respectively.

Keywords: physical properties-mechanical properties- potato tubersfriction angle- rolling angle - sphericity.

* Assist. Prof., Agric. Eng. Dept., Fac. of Agric., Cairo Univ., Giza, Egypt. 


\section{INTRODUCTION}

$\mathrm{P}$ otato (Solanum tuberosum L.) is ranked as one of the most important vegetable crops in the world; it occupies the second place in acreage and production after seed crops (Anonymous, 2010). Cultivated area of vegetables in Egypt is about 1.84 million fed, to produce $17.87 \mathrm{Tg} /$ year. Potatoes are one of the major vegetable crops in Egypt, whose cultivated area is about $178 \times 10^{3}$ hectare to produce about $4800 \times 10^{3} \operatorname{Tg}($ million ton) distributed on the summer, Nile and winter seasons. The amount of Egyptian potato exports was estimated from 250$300 \mathrm{Gg} /$ year, it reaches to $430 \mathrm{Gg}$ (thousand tons) from fresh potatoes exported to Europe and Arabic market, which gives export income 140 million U.S.\$/year (FAO Statistical Yearbook, 2013). Physical and mechanical properties of agricultural materials are essential for the design of equipment for harvesting, handling, cleaning and separating, grading, processing and storing. So a specific knowledge is necessary for associating many problems with the design or development of a specific machine, and also for analysis of equipment and systems used to process food on a commercial production scale. Although the recent scientific development have improved the handling and processing equipment of biomaterial through mechanical, thermal, electrical, optical and other techniques, little is known about the basic physical characteristics of these materials. Such basic information is important not only for engineers, but also for food scientists who may find new uses (Waziri and Mittal 1983).A better understanding of the way food materials respond to physical and chemical treatments allows for optimum design of food equipment and processes to insure food quality and safety. Knowledge of physical properties of food is necessary for defining and quantifying a description of the food material, providing basic data for food engineering and unit operations, and predicting behavior of new food materials. (Wilhelm et. al., 2004).The quality of potato tubers, as in all horticultural produce, is closely connected to the chemical and structural characteristics of plant tissues and varies widely in relation to different factors such as climate, growing conditions, cultivar and maturity at harvest and harvesting method (Bentini et al., 2006). The coefficient of friction is used to determine the angle at which chutes must be positioned in order to achieve consistent flow of material through the 
chute. In addition, this coefficient is important in the designing of conveyors because friction is necessary to hold the potato tuber to the conveying surface without slipping or sliding backward (Razavi et al. 2007).The importance of food materials tends to increase greatly with the complexity of new technology for the handling, production, processing, storage and preservation. Evaluation of quality, distribution and marketing and uses of these products depends on the knowledge of engineering properties of these materials. The handling operations can be designed to produce optimum efficiency and the maximum quality of food or end products. For instance, the application of physical properties such as shape is an importance parameter for stress distribution in materials under load is important in developing of sizing and grading machines and for analytical predictions of its drying behavior. Density, size, and drag coefficients are important in calculation of terminal velocity of an object in fluid (Esref and Halil, 2007). The physical properties of different fruits and vegetables have been determined by other researcher; caper fruit (Sessizet al. 2007), potato (Tabatabaeefar 2002), apple (Meisami-asl et al. 2009). (Safa and Khazaei 2003) studied the physical properties of pomegranate and found models of predicting fruit mass based on the dimensions, volume and surface area. In most industrial, developed and developing countries, potato has particular importance in the food chain among agricultural products. The amount of energy in this product is 830 calories per $\mathrm{kg}$. Twenty million hectares cultivated potato to cover 130 countries ( $75 \%$ of the world's population) of their need of potato. The annual production of potato is 280 million tons, which makes it the fourth major crop plant in the world after wheat, rice and corn (Ahangarnezhad 2009). The quality of food materials can be assessed by measuring their densities. Density data of foods are required in separation processes, such as centrifugation and sedimentation, and in pneumatic and hydraulic transport of powders and particulates (Sahina and Gülüm 2006) and (Gorji et al. 2010). (Elghobashy el al. 2014) mentioned that the properties of potato tuber dimensions were mainly to design the pocket sizes which must be equal or greater than the maximum dimensions of the three tuber mass categories for two varieties. The maximum sizes (length and width) for first categories were 105.2, $63.1 \mathrm{~mm}$ and 79.2, $67.1 \mathrm{~mm}$. For second categories, were 121.2 
$69.4 \mathrm{~mm}$ and 89.1, 77.2 $\mathrm{mm}$, and for third categories were 155.0, 69.1 $\mathrm{mm}$ and 107.7, $87.2 \mathrm{~mm}$ for the varieties of Sponta and Diamond, respectively.

The object of the research is to study some physical and mechanical properties of some different varieties of potatoes, as data base, to help the designers for handling machines in order to determine the best post-harvest options. Therefore, design for sorting, cleaning and grading machine can be suggested taking in consideration the physical and mechanical properties of potatoes.

\section{MATERIAL AND METHODS}

The tests were conducted using three potato cultivars (Astrix, Diamont and Santana) which using widely-grown in Egypt. The tubers were obtained from Horticultural Research Institute (H.R.I), Agricultural Research Center (A.R.C) Giza, Egypt and the measurements were taken in the same day. The initial moisture content of the potato tubers was determined using the oven method (ASAE Standard 1998) and obtained as $82 \%$ (w.b).

\section{Instruments:}

-Digital balance: To measure mass of potatoes tuber with accuracy of $0.1 \mathrm{~g}$. -Digital caliper with venire: To measure different dimensions of potatoes tuber (length, Width, and thickness $\mathrm{mm}$ ) with accuracy of $0.01 \mathrm{~mm}$.

-Friction and rolling-angle measuring device: To measure friction and rolling angle, with accuracy of 0.5 degree.

\section{Physical properties of potato tubers :}

A random sample of one hundred potatoes tuber was taken from potatoes fields (Astrix, Diamont and Santana variety) to measure physical and mechanical properties. All treatments were replicated five times to give more reliable average.

Dimensions like length (L), width (W), and thickness (T) mm, mass (M) $\mathrm{g}$, volume $(\mathrm{V}) \mathrm{cm}^{3}$, true density $\left(\rho_{\mathrm{t}}\right) \mathrm{g} / \mathrm{cm}^{3}$, sphericity $(\mathrm{S}) \%$, geometric diameter $(\mathrm{Gd}) \mathrm{mm}$, and arithmetic diameter $(\mathrm{Ad}) \mathrm{mm}$, for potatoes tubers are reported according to El-Raie et al. (1996) as follows:-

$$
\begin{aligned}
& \mathrm{V}=\pi / 6(\mathrm{~L} \times \mathrm{W} \times \mathrm{T}), \mathrm{mm}^{3} \\
& \mathrm{~S}=100 \times(\mathrm{L} \times \mathrm{W} \times \mathrm{T})^{1 / 3} / \mathrm{L}, \% \\
& \mathrm{Gd}=(\mathrm{L} \times \mathrm{W} \times \mathrm{T})^{1 / 3}, \mathrm{~mm} \\
& \mathrm{Ad}=(\mathrm{L}+\mathrm{W}+\mathrm{T}) / 3, \mathrm{~mm}
\end{aligned}
$$




$$
\rho_{\mathrm{t}}=\mathbf{M} / \mathbf{V}
$$

\section{Mechanical properties of potato tubers :}

\section{Rolling-angle measurement:}

The potatoes tubers are placed on a horizontal surface one by one then the angle of inclination is gradually increased until the tubers begin to roll. For each fruit of an (50) average sample, the angle was determined for the maximum stable.

\section{Friction-angle measurement:}

The potatoes tubers are placed as a group bounded together on a horizontal surface then the angle of inclination is gradually increased until the fruits begin sliding without rolling. For each fruits group of an (10) average sample, the friction angles were determined.

\section{Coefficient of friction:}

From friction angle, the coefficient of friction of the sample was estimated according the following equation:

$$
\boldsymbol{\mu}=\tan \boldsymbol{\theta}
$$

Where:

$$
\begin{aligned}
& \mu=\text { Coefficient of friction } \\
& \theta=\text { Friction angle, deg. }
\end{aligned}
$$

Suggesting design of sorting, cleaning and grading machine for potato tubers:

Fig. 1 shows a schematic diagram of a suggesting design for sorting, cleaning and grading machine.

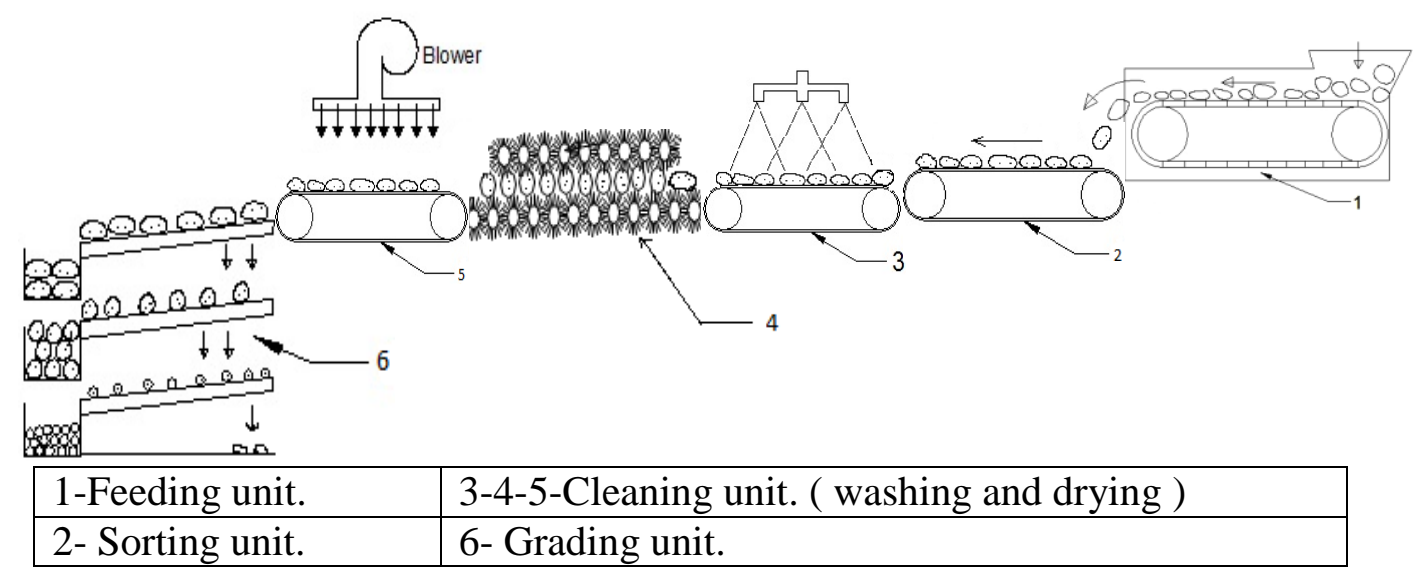

Fig. 1: Diagram demonstrating a suggesting design for sorting, cleaning and grading machine. 
Associated parameters:

(1) Fruit dimensions

(3) Fruit mass and volume

(2) Friction and rolling angle

\section{RESULTS AND DISCUSSION}

1- Physical properties of potato tubers varieties:

The obtained physical properties are illustrated in table (1).

Table 1 : Physical properties of three potato tubers varieties "Astrix, Diamont and Santana".

\begin{tabular}{|c|c|c|c|c|c|}
\hline \multirow[t]{2}{*}{ Physical properties } & \multicolumn{5}{|c|}{ Potato tubers "variety of Astrix" } \\
\hline & Max. & Min. & Average & S. D. ${ }^{(1)}$ & C. V. ${ }^{(2)}$ \\
\hline Length, mm & 127.68 & 39.25 & 74.99 & 20.654 & 27.545 \\
\hline Width, mm & 67.4 & 32.27 & 47.79 & 9.252 & 19.362 \\
\hline Thickness, mm & 53.32 & 25.38 & 38.65 & 6.572 & 16.993 \\
\hline Sphericity, \% & 81.02 & 60.41 & 69 & 5.081 & 7.251 \\
\hline Mass, g & 284.43 & 27.97 & 96.35 & 64.725 & 67.174 \\
\hline Volume, $\mathbf{m m}^{3}$ & 240254.502 & 16831.734 & 72525.128 & 55462.035 & 69.791 \\
\hline Density, $\mathrm{g} / \mathrm{cm}^{3}$ & 1.363 & 0.921 & 1.176 & 0.078 & 6.275 \\
\hline Geometric diameter, mm & 77.130 & 31.80 & 51.74 & $\mathbf{1 0 . 8 3 5}$ & 20.963 \\
\hline Arithmetic diameter, mm & 82.8 & 32.3 & 53.81 & 11.993 & 22.299 \\
\hline \multirow[t]{2}{*}{ Physical properties } & \multicolumn{5}{|c|}{ Potato tubers "variety of Diamont" } \\
\hline & Max. & Min. & Average & S. D. ${ }^{(1)}$ & C. V. ${ }^{(2)}$ \\
\hline Length, mm & 103.3 & 32.37 & 64.79 & $\mathbf{1 7 . 1 3 0}$ & 26.447 \\
\hline Width, mm & 64.69 & 28.65 & 45.12 & 9.126 & 20.226 \\
\hline Thickness, mm & 55.31 & 26.02 & 39.81 & 6.951 & 17.471 \\
\hline Sphericity, \% & 69.40 & $\mathbf{8 9 . 2 8}$ & 75.35 & 7.293 & 9.524 \\
\hline Mass, $\mathrm{g}$ & 202.95 & 17.42 & 78.41 & 50.485 & 64.390 \\
\hline Volume, $\mathbf{m m}^{3}$ & 193526.193 & 12634.942 & 60935.148 & 40622.761 & 59.900 \\
\hline Density, $\mathrm{g} / \mathrm{cm}^{3}$ & 1.377 & 0.763 & 1.149 & 0.103 & 8.889 \\
\hline Geometric diameter, $\mathbf{m m}$ & 71.69 & 28.90 & 48.82 & 9.929 & 20.387 \\
\hline Arithmetic diameter, $\mathbf{m m}$ & $\mathbf{7 4 . 4 3}$ & 29.01 & 49.91 & 10.569 & 21.179 \\
\hline \multirow[t]{2}{*}{ Physical properties } & \multicolumn{5}{|c|}{ Potato tubers "variety of Santana" } \\
\hline & Max. & Min. & Average & S. D. ${ }^{(1)}$ & C. V. ${ }^{(2)}$ \\
\hline Length, mm & 151.8 & 46.43 & 98.78 & 25.214 & 25.529 \\
\hline Width, mm & 75.12 & 41.92 & 58.19 & 8.304 & 14.275 \\
\hline \begin{tabular}{|l|} 
Thickness, mm \\
\end{tabular} & 55.4 & 33.26 & 44.14 & $\mathbf{5 . 7 7 0}$ & $\mathbf{1 3 . 0 8 7}$ \\
\hline Sphericity, \% & 56.52 & 86.47 & 64.10 & 9.736 & 14.813 \\
\hline Mass, $\mathbf{g}$ & 338.61 & 62.75 & 167.21 & 82.431 & 49.293 \\
\hline Volume, $\mathbf{m m}^{3}$ & 330777.330 & 33895.405 & 132845.954 & 73783.965 & 51.748 \\
\hline Density, $\mathrm{g} / \mathrm{cm}^{3}$ & 2.2815 & 1.0686 & 1.193 & 0.191 & 16.608 \\
\hline Geometric diameter, $\mathbf{m m}$ & 85.80 & 40.15 & 63.31 & 10.637 & 16.861 \\
\hline Arithmetic diameter, $\mathbf{m m}$ & 4.11 & 40.54 & 67.04 & 12.484 & 18.624 \\
\hline
\end{tabular}

(1) S. D. is standard deviation.

(2) C. $V$. is coefficient of variation. 


\section{Dimensions :}

Table (1) and figure (2) show the average dimensions of three potato cultivars "Astrix, Diamont and Santana" used in the experiments are as follows:

$\mathrm{L}=74.99 \mathrm{~mm}, \mathrm{~W}=47.79 \mathrm{~mm}$ and $\mathrm{T}=38.65 \mathrm{~mm}$ for potato tubers "Variety of Astrix".

$\mathrm{L}=64.79 \mathrm{~mm}, \mathrm{~W}=45.12 \mathrm{~mm}$ and $\mathrm{T}=39.81 \mathrm{~mm}$ for potato tubers "Variety of Diamont".

$\mathrm{L}=98.78 \mathrm{~mm}, \mathrm{~W}=58.19 \mathrm{~mm}$ and $\mathrm{T}=44.14 \mathrm{~mm}$ for potato tubers "Variety of Santana".

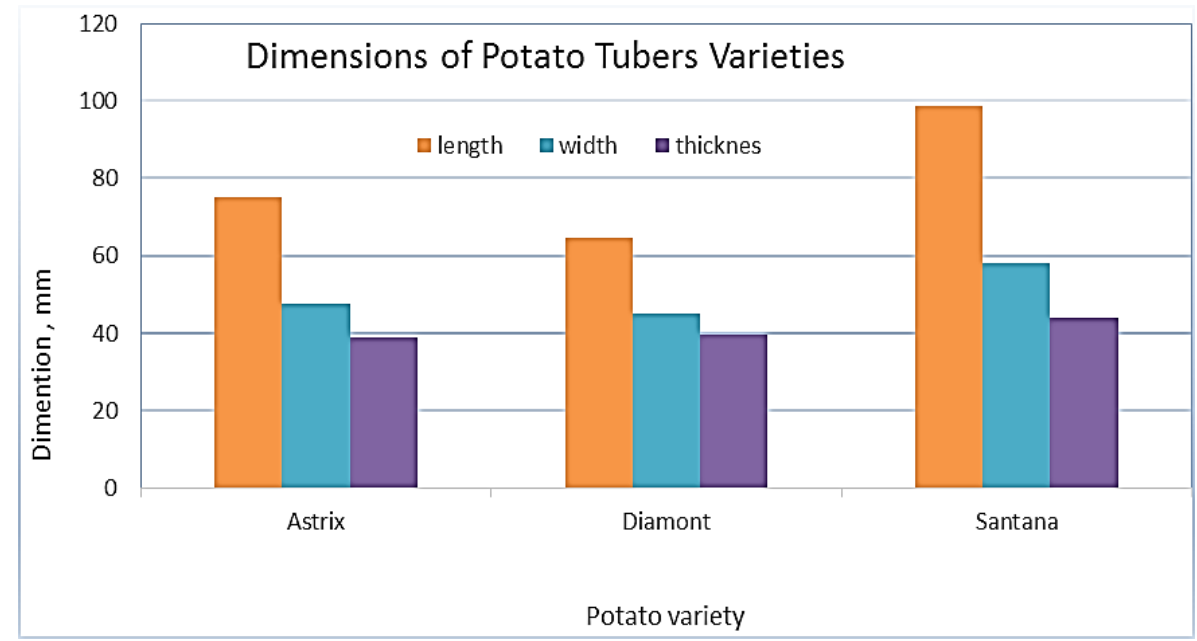

Fig (2) Different dimensions for potato varieties.

Frequency distribution curves for the three dimension of the three potato tubers varieties are show in Fig (3).The most frequent percent (78\%)in the sample for Astrix variety have 50-90mm length, (69\%)in the sample for Diamont variety have $50-80 \mathrm{~mm}$ length and $(50 \%)$ in the sample for Santana variety have $70-100 \mathrm{~mm}$ length. The most frequent percent (68\%)in the sample for Astrix variety have 40-60mm width, $(85 \%)$ in the sample for Diamont variety have $30-60 \mathrm{~mm}$ width and $(91 \%)$ in the sample for Santana variety have $40-70 \mathrm{~mm}$ width. The most frequent percent (84\%)in the thickness sample for Astrix variety have $30-50 \mathrm{~mm}$, $(90 \%)$ in the sample for Diamont variety have 30-50mm thickness and $(100 \%)$ in the sample for Santana variety have 30-60mm thickness. 


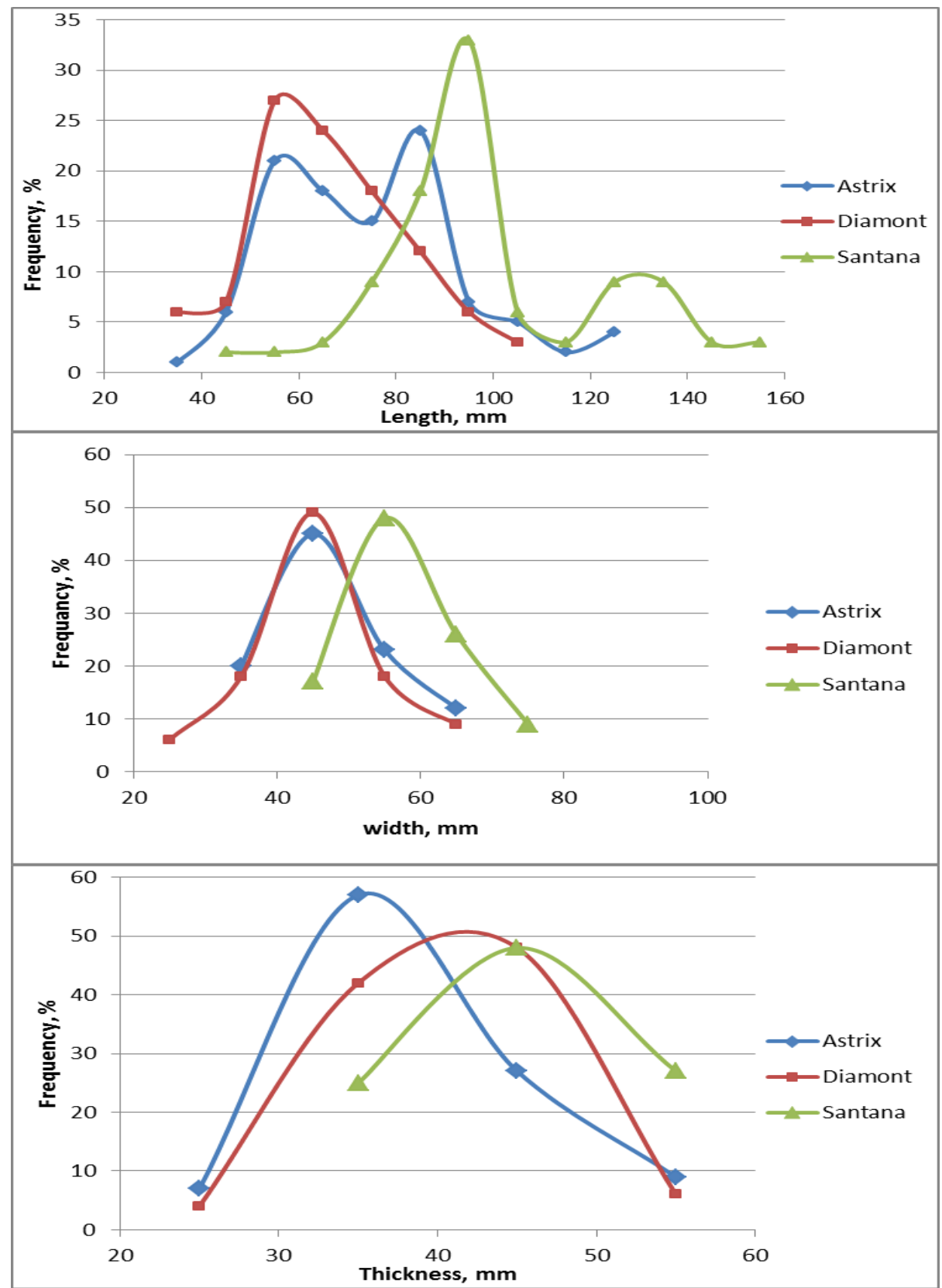

Fig. 3: Frequency distribution curves for three potato tubers dimensions of Astrix, Diamont and Santana varieties.

\section{sphericiety:}

Buyanov and Voronyuk ( 1985) mentioned that, if sphericity is less than 0.9 , the fruit belongs to oblate group , and if it is greater than 1.1 it belongs to oblong group. The remaining fruits with intermediate index 
values are considered to be round. The data indicated that the fruit sphericity ranged in sample between 60.41 and $81.02 \%$ (average 69\%), 69.40 and $89.28 \%$ (average $75.35 \%$ ) and 56.52 and $86.47 \%$ (average $64.10 \%$ ) for Astrix, Diamont and Santana potato varieties, respectively.

\section{Mass, volume and true density:}

The data as shown in table (1) indicated that the Astrix, Diamont and Santana potato varieties mass ranges of sample were 27.97-284.43 g, (average 96.35 g), 17.42-202.95 g, (average 78.41g) and 62.75-338.61 g (average $167.21 \mathrm{~g}$ ), respectively.

Also, the fruit volume ranges of sample were 16831.734-240254.502 $\mathrm{mm}^{3}$ (average $72525.128 \mathrm{~mm}^{3}$ ), $12634.942-193526.193 \mathrm{~mm}^{3}$ (average $60935.148 \mathrm{~mm}^{3}$ ) and $33895.405-330777.330 \mathrm{~mm}^{3}$ (average 132845.954 $\mathrm{mm}^{3}$ ), respectively. While true density ranges of sample were 0.921$1.363 \mathrm{~g} / \mathrm{cm}^{3}$, (average $1.176 \mathrm{~g} / \mathrm{cm}^{3}$ ), 0.763-1.377 g/cm ${ }^{3}$, (average 1.149 $\mathrm{g} / \mathrm{cm}^{3}$ ) and $1.0686-2.2815 \mathrm{~g} / \mathrm{cm}^{3}$ (average $1.193 \mathrm{~g} / \mathrm{cm}^{3}$ ), respectively.

\section{Geometric diameter and arithmetic diameter :}

The data as shown in table (1) indicated that the mean values of geometric diameter for Astrix, Diamont and Santana potato variety were reported as 51.74, 48.82and $63.31 \mathrm{~mm}$, respectively. Also, the mean values of arithmetic diameter for Astrix, Diamont and Santana potato variety were reported as 53.81, 49.91 and $67.04 \mathrm{~mm}$, respectively.

\section{2- Mechanical properties of potato tubers cultivars:}

Friction angle, coefficient of friction and rolling angle of potato tubers cultivars:

Table (2) shows friction angle, coefficient of friction and rolling angles of potatoes tubers cultivars on rubber, galvanized steel sheet, iron sheet and aluminum surface.

The maximum friction angle of 28.6, 22.2 and 30.4 degree and rolling angle of 24.8, 20.2 and 27.4 degrees were obtained with rubber surface. The coefficient of friction were $0.545,0.408$ and 0.586 with rubber surface for Astrix, Diamont and Santana potato varieties, respectively. Whereas, the minimum friction angle of 16.3, 14.0 and 18.7 degree and rolling angle of 14.0, 13.3 and 15.5 degree. The coefficient of friction were $0.292,0.249$ and 0.338 with aluminum surface for Astrix, Diamont and Santana potato varieties respectively. Fig. (4) shows friction angles of potato varieties on different surface types, while Fig. (5) shows rolling angles of potato varieties on different surface types. 
Table 2: Mechanical properties of potatoes cultivars "Astrix, Diamont and Santana" with different surface types.

\begin{tabular}{|c|c|c|c|c|}
\hline \multirow[t]{3}{*}{ Mechanical properties } & \multicolumn{4}{|c|}{ Potatoes tubers "variety of Astrix" } \\
\hline & \multicolumn{4}{|c|}{ Surface type } \\
\hline & $\begin{array}{c}\text { Galvanized } \\
\text { steel sheet }\end{array}$ & Rubber & Iron sheet & Aluminum \\
\hline Friction angle, degree & 16.8 & 28.6 & 23.9 & 16.3 \\
\hline Coefficient of friction & 0.302 & 0.545 & 0.433 & 0.292 \\
\hline Rolling angle, degree & 14.8 & 24.8 & 19.5 & 14.0 \\
\hline \multirow[t]{3}{*}{ Mechanical properties } & \multicolumn{4}{|c|}{ potatoes tubers (Variety of Diamont) } \\
\hline & \multicolumn{4}{|c|}{ Surface type } \\
\hline & $\begin{array}{l}\text { Galvanized } \\
\text { steel sheet }\end{array}$ & Rubber & Iron sheet & Aluminum \\
\hline Friction angle, degree & 14.6 & 22.2 & 18.9 & 14.0 \\
\hline Coefficient of friction & 0.260 & 0.408 & 0.342 & 0.249 \\
\hline Rolling angle, degree & 13.8 & 20.2 & 16.6 & 13.3 \\
\hline \multirow[t]{3}{*}{ Mechanical properties } & \multicolumn{4}{|c|}{ Potatoes tubers "variety of Santana" } \\
\hline & \multicolumn{4}{|c|}{ Surface type } \\
\hline & $\begin{array}{l}\text { Galvanized } \\
\text { steel sheet }\end{array}$ & Rubber & Iron sheet & Aluminum \\
\hline Friction angle, degree & 19.4 & 30.4 & 26.70 & 18.7 \\
\hline Coefficient of friction & 0.352 & 0.586 & 0.523 & 0.338 \\
\hline Rolling angle, degree & 16.3 & 27.4 & 22.5 & 15.5 \\
\hline
\end{tabular}

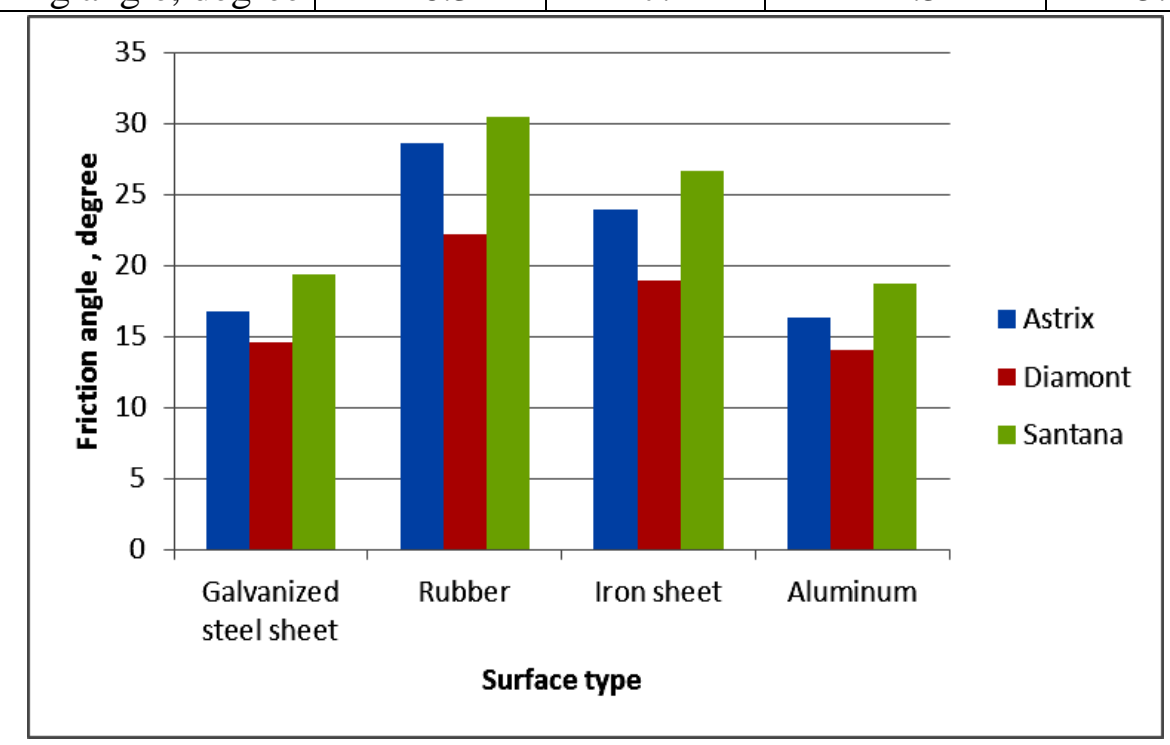

Fig (4) Friction angles of potato varieties on different surface types 


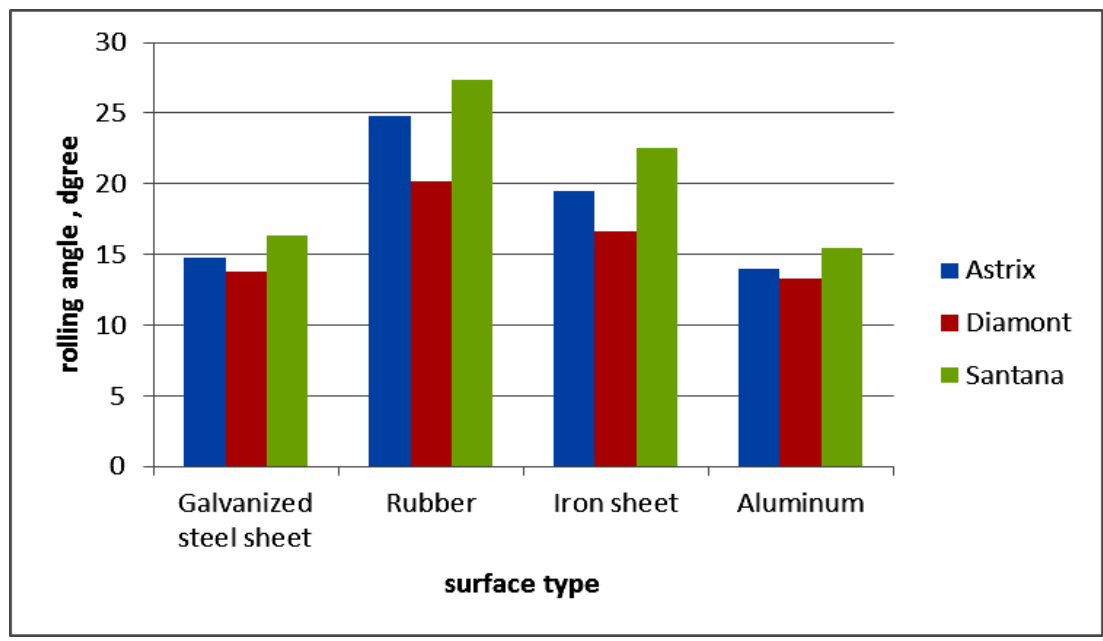

Fig (5) Rolling angles of potato varieties on different surface types 3- Theoretical application for suggesting design of potato cleaning and grading machine

Parameters required for development of the design of sorting, cleaning and grading machine have been explained in the second part in the section on "materials and methods" .Some results of this investigation point out to the following:

\section{Feeding unit:}

Fruit hopper dimensions: To suit feeding unit, feed rat of fruits $=160 \mathrm{x}$ $100 \times 50 \mathrm{~cm}$ for length, width and height respectively.

Fruit hopper side-slop $=$ more than friction and rolling angle between potato fruits and iron sheet $=35$ degree.

\section{Spaced bar conveyor:}

Roller-bar spacing $=$ less than the minimum thickness of potato fruits $=$ $24 \mathrm{~mm}$ to suit the size of potato fruits.

Roller-bar material is rubber.

Conveyor dimensions: length of $160 \mathrm{~cm}$ and width of $100 \mathrm{~cm}$.

\section{Sorting unit:}

Conveyor dimensions: It was designed according to fruit dimensions $=$ length of $150 \mathrm{~cm}$ and width of $100 \mathrm{~cm}$.

Conveyer material $=$ pelt of rubber or pipe of aluminum.

\section{Cleaning units:}

Roller without hairs diameter $=50 \mathrm{~mm}$

Hair length $=15 \mathrm{~mm}$.

Roller spacing $=20 \mathrm{~mm}$ to suit the size of potato. 


\section{Grading units:}

It is consists of three reciprocating sieves to grade the fruits to four sizes. Hole shape $=$ ellipse.

Hole length $=100,80$ and $60 \mathrm{~mm}$ for three sieves.

Hole width $=60,50$ and $40 \mathrm{~mm}$ for three sieves. The fourth size drops on solid sheet underneath the bottom sieve.

Slope of sieves $=$ less than the friction and rolling angle of potato fruits $=$ 10 degree.

Slope of solid sheet $=$ more than the friction and rolling angle of potato fruits $=20$ degree.

Grading-unit material $=$ Galvanized steel sheet or Aluminum .

\section{CONCLUSION}

Mean values of length, width, thickness, mass, volume, true density, sphericity, geometric diameter, and arithmetic diameter were74.99 mm, $47.79 \mathrm{~mm}, 38.65 \mathrm{~mm}, 96.35 \mathrm{~g}, 72525.128 \mathrm{~mm}^{3}, 1.176 \mathrm{~g} / \mathrm{cm}^{3}, 69 \%$, $51.74 \mathrm{~mm}$ and $53.81 \mathrm{~mm}$, respectively for potato tubers "variety of Astrix". Meanwhile were $64.79 \mathrm{~mm}, 45.12 \mathrm{~mm}, 39.81 \mathrm{~mm}, 78.41 \mathrm{~g}$, $60935.148 \mathrm{~mm}^{3}, 1.149 \mathrm{~g} / \mathrm{cm}^{3}, 75.35 \%, 48.22 \mathrm{~mm}$ and $49.91 \mathrm{~mm}$, respectively for potato tubers "variety of Diamont". And for variety of Santana were $98.78 \mathrm{~mm}, 58.19 \mathrm{~mm}, 44.14 \mathrm{~mm}, 167.21 \mathrm{~g}, 132845.954$ $\mathrm{mm}^{3}, 1.193 \mathrm{~g} / \mathrm{cm}^{3}, 64.10 \%, 63.31 \mathrm{~mm}$ and $67.04 \mathrm{~mm}$, respectively. The maximum friction angle of 28.6, 22.2 and 30.4 degree and rolling angle of 24.8, 20.2 and 27.4 degrees were obtained with rubber surface. While, the minimum friction angle of 16.3, 14.0 and 18.7 degree and rolling angle of 14.0, 13.3 and 15.5 degree were obtained with aluminum surface for Astrix, Diamont and Santana potato varieties, respectively. The obtained data helps to understand the behavior of the product during the post harvesting operations and in design or redesign the machines for harvesting potato to increase its efficiency.

\section{REFERENCES}

Ahangarnezhad, N. (2009). Design and Fabrication of Bagging Mechanism for Potato Picking Machine.M.sc Thesis University of Tehran, Iran.

Anonymous, A. (2010). Annual Report. Tuber Crops Research Centre, BARI, Joydebpur, Gazipur.202p. 
ASAE Standards (1998). S368.2. Compression Test of Food Materials of Convex Shape (44th ed.). American Society for Agricultural Engineering, St. Joseph, Michigan.

Bentini M.; Caprara C. and Martelli R. (2006). Harvesting Damage to Potato Tubers by Analysis of Impacts Recorded with an Instrumented Sphere. Biosystems Engineering, Postharvest Technology, 94 (1), 75-85.

Buyanov, A. I. and B. A. Voronyuk (1985).Physical and mechanical properties of plant, Fertilizers and soils.Amerind Pub. Co., PVT., LTD., New Delhi, India.753 P.

El-Raie; A.E.E.; N. A. Hendawy and A.Z. Taib, (1996); Study of physical and engineering properties for some agricultural products.Misr. J. Ag. Eng., 13 (1) : 211-226.

Elghobashy, H.; I. Yehia and Y. A. Shaaban (2014). Development Of the potato tuber cutting prototype. Misr J. Ag. Eng., 31(4): 1395 1412.

Esref, I. and Halil, U. (2007). Moisture dependent Physical Properties of White Speckled Red Kidney Bean Grains. Journal of Food Engineering, 82: 209-216.

FAO Statistical Yearbook (2013). Area harvested and production of starchy roots and tubers.

Gorji A.; Rajabipour A. and Mobli H. (2010). Post Harvest Physical and Nutritional Properties of Two Apple Varieties .Journal of Agricultural Science. 2( 3): 1-8.

Meisami-asl E.; Rafiee S., Keyhani A. and Tabatabaeefar A.(2009). Some physical properties of apple cv. 'Golab'.The CIGR E journal .Vol. XI.

Razavi S.M.A.; Emadzadeh B.; Rafe A. and Mohammad Amini A. (2007) . The physical properties of pistachio nut and its kernel as a function of moisture content and variety: Part I. Geometrical properties. Journal of Food Engineering. 81: 209-217.

Safa M. and Khazaei J. (2003). Determining and modeling some physical properties of pomegranate fruits of Saveh area related to peeling and packaging. In: International Congress on Information Technology in Agriculture, Food and Environment, Izmir, Turkey, 7-10 October. pp. 331-337.

Sahin S. and GülümSumnu S. (2006). Physical properties of foods. Springer publisher 
Sessiz A.; Esgici R. and Kizil S. (2007).Moisture-dependent physical properties of caper (Capparis ssp.) fruit. Journal of Food Engineering.79: 1426- 1431.

Tabatabaeefar A. (2002). Size and shape of potato tubers. International Agrophysics. 16: 301-305.

Waziri, A. N. and J. P. Mittal, (1983). Design related physical properties of selected agricultural products. Agric. Mech. in Asia. Africa. Latin America. Vol. 14 (1):59 - 62.

Wilhelm L.; Dwayne R.; Suter A.; Gerald H. (2004). Physical properties of food materials. St. Joseph, Michigan: ASAE. 23-52.

\section{الملخص العربي \\ تقدير بعض الخواص الطبيعية والميكانيكية لارنات البطاطس المرتبطة والبطة بتصميم

$$
\begin{aligned}
& \text { آلة للفرز والتنظيف والتدريج } \\
& \text { يسري بيومي عبد الحيث }
\end{aligned}
$$

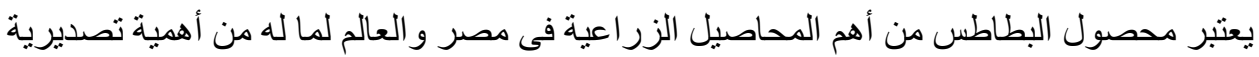

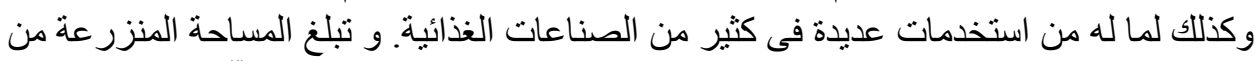

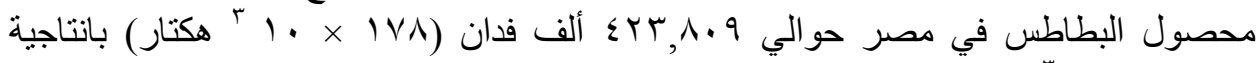



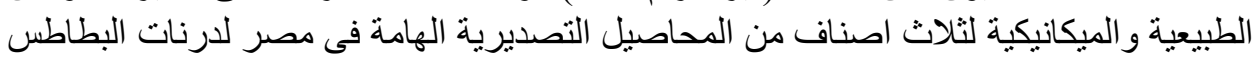

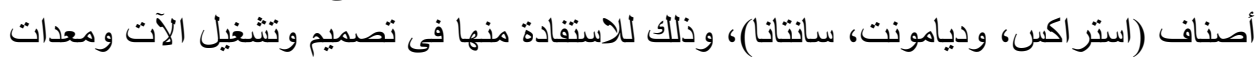

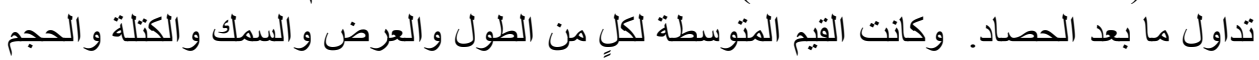

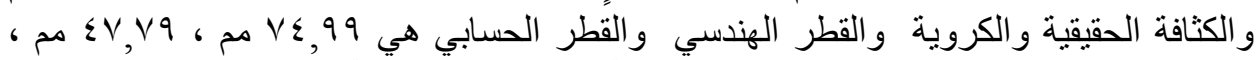

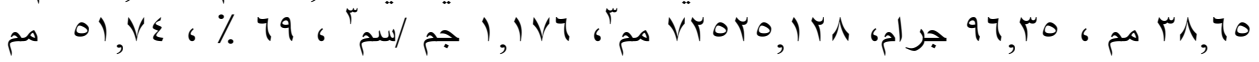

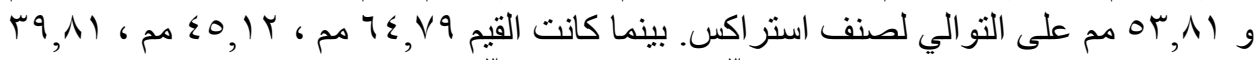

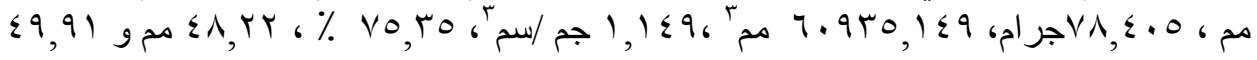

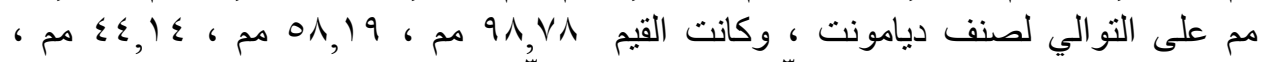

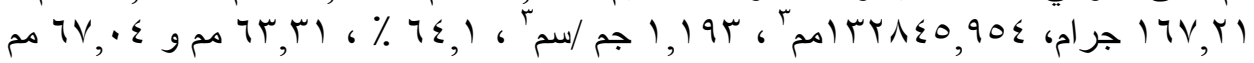

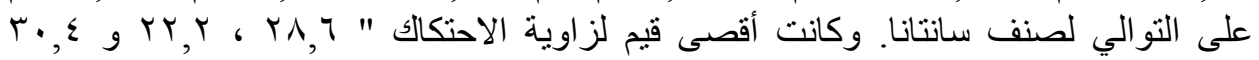

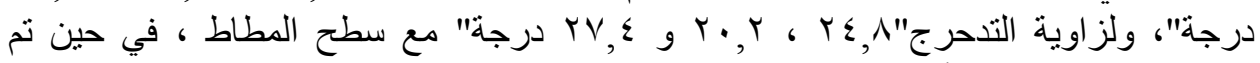

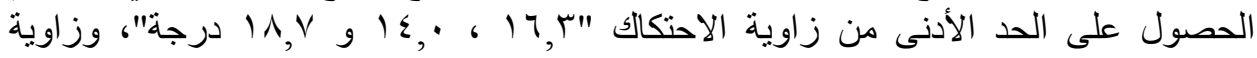

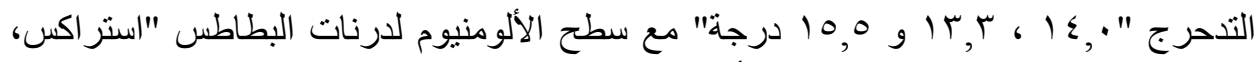



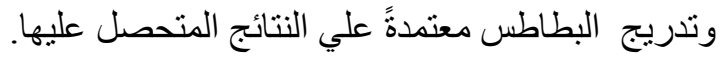

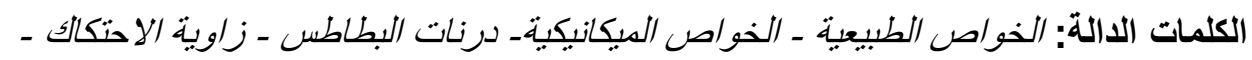
زاوية التنرحرج - الكروية. 